\title{
Variability in the Slope Water and its relation to the Gulf Stream path
}

\author{
B. Peña-Molino ${ }^{1}$ and T. M. Joyce ${ }^{2}$ \\ Received 27 September 2007; revised 3 December 2007; accepted 13 December 2007; published 6 February 2008.
}

[1] Sea Surface Temperature (SST) and Sea Surface Height (SSH) data for 1993-2007 for the North Atlantic are combined with hydrographic data at $69 \mathrm{~W}$ to investigate the relation between the Gulf Stream (GS) position and the Slope Water properties. SST anomalies north of the GS are correlated with changes in its path. The lag of this correlation is such that positive temperature anomalies precede northward shifts of the GS, and suggests that SST anomalies move westward with speeds of several $\mathrm{cm} / \mathrm{s}$. EOF analysis of the SST and SSH fields shows that cooling and strengthening of the SW flow are in phase over the Slope Water, which is mirrored in the vertical structure of these fields at $69 \mathrm{~W}$, indicating larger transports in the Deep Western Boundary Current lead to southward shifts of the mean GS path. This relation between the Slope Water and the GS path provides some predictability for the latter. Citation: Peña-Molino, B., and T. M. Joyce (2008), Variability in the Slope Water and its relation to the Gulf Stream path, Geophys. Res. Lett., 35, L03606, doi:10.1029/2007GL032183.

\section{Introduction}

[2] Two of the major currents in the North Atlantic are the Deep Western Boundary Current (DWBC), which carries cold waters from high to low latitude, and the Gulf Stream, which carries warm waters from low to high latitudes. They are fundamental elements of the Meridional Overturning Circulation, and their variability has important consequences on the ocean's heat transport.

[3] A large fraction of the Gulf Stream variability is related to fluctuations of its path. [Lee and Cornillon, 1995] showed that these fluctuations consist of two modes: meanders, with typical length scales of $100 \mathrm{~km}$ and periods ranging from 2 to 60 days, and latitude shifts that penetrate $1000 \mathrm{~km}$ into the basin and fluctuate at time scales ranging from several months to several years. The latter has been attributed to atmospheric forcing [Kelly et al., 1996; Frankignoul et al., 2001; Joyce et al., 2000], internal dynamics of the jet [Berloff et al., 2007], and interactions with the DWBC [Thompson and Schmitz, 1989; Spall, 1996; Bower and Hunt, 2000; Pickart and Smethie, 1993; Joyce et al., 2000; Ezer and Mellor, 1992; Zhang and Vallis, 2007]. In the present study we provide observational evidence of the role the circulation in the Slope Water, and the DWBC as one of its components, may play in the variability of the GS path. The mechanism governing the interaction between the Gulf Stream and DWBC is beyond the scope of this study.

\footnotetext{
${ }^{1}$ MIT-WHOI Joint Program, Woods Hole, Massachusetts, USA. ${ }^{2}$ Woods Hole Oceanographic Institution, Woods Hole, Massachusetts, USA.
}

Copyright 2008 by the American Geophysical Union. 0094-8276/08/2007GL032183\$05.00
[4] Observational and modeling studies have shown that the Gulf Stream and the DWBC get significantly modified at the cross-over, where the Gulf Stream separates from the coast and the DWBC is forced to flow underneath it [Spall, 1996; Bower and Hunt, 2000; Pickart and Smethie, 1993]. However, the nature of this interaction and how it affects the GS path is not quite understood yet. Thompson and Schmitz [1989] found using a two layer model that stronger DWBC transports lead to a southerly Gulf Stream. Similar results were found by others [Spall, 1996; Joyce et al., 2000; Ezer and Mellor, 1992] using different models. In a more recent study [Zhang and Vallis, 2007] found that the Northern Recirculation Gyre (NRG) was responsible for maintaining the GS path separated from the coast. According to their results the formation of the NRG was linked to changes in the strength of the DWBC.

[5] To investigate the relationship between the DWBC and the GS path from an observational framework SST and SSH are utilized to characterize the surface signal of the GS path and the Slope Water currents. In situ velocity, temperature and salinity from a series of repeat hydrographic sections are employed to describe how the surface variability relates to the deeper flow including the DWBC.

\section{Data}

\subsection{Remote Sensing}

[6] Monthly SST anomalies for 1993 to 2007 were obtained from the Reynolds data set (see Reynolds et al. [2006] for details). The spatial resolution of the data is $1 / 4^{\circ} \times$ $1 / 4^{\circ}$. The seasonal cycle was removed from the data, and the SST anomalies obtained by subtracting the time mean for the whole period at each point.

[7] SSH anomalies for the same time period were obtained from the satellites TOPEX-Poseidon and Jason. The data were corrected for atmospheric effects, surface conditions and other contributions such as tides and inverse barometer effect, and the long term mean removed. Along track data were provided every 10 days.

\subsection{Hydrographic Data}

[8] In order to study the vertical structure of the variability in the Slope Water a total of 7 hydrographic surveys were employed. The stations were collected along Line W (http://www.whoi.edu/science/PO/linew/index.htm), a transect across the DWBC located at approximately $69 \mathrm{~W}$ and coincident with TOPEX-Poseidon altimeter track 126. The data used here consist of velocity and CTD measurements, spanning the period of 2003 to 2006 . The sections were typically done at mid-spring and mid-fall. To minimize the direct effect of the Gulf Stream, stations offshore of the $4500 \mathrm{~m}$ isobath were neglected. The sections were interpolated into a regular $20 \mathrm{~km} \times 50 \mathrm{~m} \mathrm{x}-\mathrm{z}$ grid, and a least- 

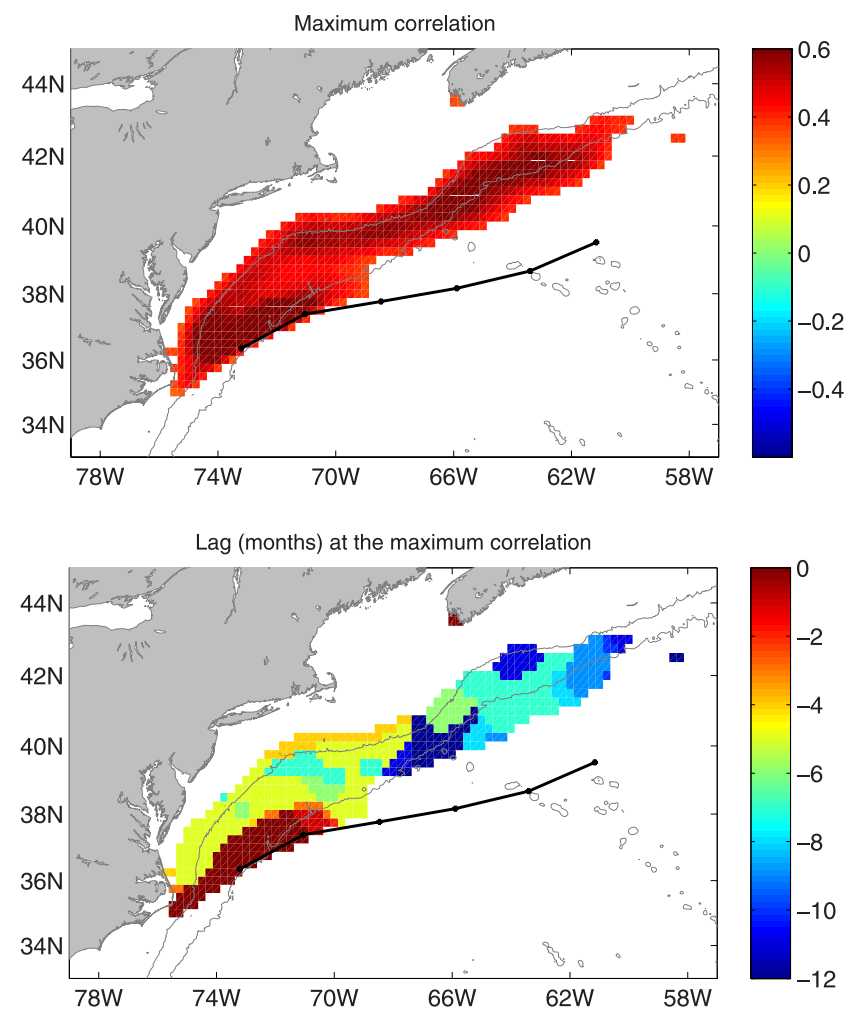

Figure 1. (top) Maximum correlation and (bottom) lag, in months, at the maximum correlation. Values below the $90 \%$ significance level have been masked out. The black line is the mean position of the Gulf Stream. Grey contours represent the 1000 and $3500 \mathrm{~m}$ isobaths.

squares estimate of the seasonal cycle removed from the CTD data.

\section{Surface Signal}

\subsection{SST and the Gulf Stream PC1 Lag-Correlation}

[9] Following the method described by Kelly and Gille [1990], the position of the Gulf Stream was estimated from the 10-day SSH anomalies along 6 descending altimeter tracks. Monthly averages were taken and the time series normalized by their standard deviation in order to minimize the effect of the downstream increase in meandering amplitude [Cornillon, 1986]. The first Empirical Orthogonal Function (EOF) of the GS path explains 30\% of the variance. EOF1 is characterized by a shift of the Gulf Stream axis similar to the lateral shift mode described by Lee and Cornillon [1995]. A large fraction of the variability in the time component of this first mode, PC1, is explained by frequencies lower than annual (Figure 4a). Its spectrum (not shown here) shows significant energy at the 2 to 3 year band.

[10] It has been observed by several authors that fluctuations in the GS path are correlated with SST changes onshore of it [Frankignoul et al., 2001; Rossby and Benway, 2000]. To investigate the structure of this relation, lagcorrelations between the GS PC1 and the SST anomalies were calculated. The results for the $90 \%$ significance level are shown in Figure 1.
[11] Maximum correlations are found to be significant north of the Gulf Stream, in a well defined pattern centered between the 1000 and $3500 \mathrm{~m}$ isobaths. The correlation is positive, meaning that warming (cooling) is associated with northward (southward) shifts of the Gulf Stream. The sign of the lag, negative over most of the slope, is such that SST changes precede shifts of the GS path, as found by other authors [e.g., Rossby, 1999; Rossby and Benway, 2000]. However, its magnitude is not uniform. At the separation point and in the deeper water west of $70 \mathrm{~W}$ the value of the lag is zero, due to the direct influence of Gulf Stream excursions. The lag is larger in the eastern part of the domain, and decreases toward the separation point, suggesting that SST anomalies correlated with GS path changes are slowly moving westward. This westward propagation does not occur at all frequencies. The coherence between the SST and the GS PC1 reveals that only periods longer than 2 years (freq $<0.04$ cycles per month) are coherent everywhere in the slope. The speed calculated from the coherence phase of the freq $<0.04 \mathrm{cpm}$ band is $-12 \pm 3 \mathrm{~cm} / \mathrm{s}$ (error bars at the 90\% significance level).

\subsection{Modes of Surface Velocity and SST Variability}

[12] To further characterize the spatially averaged low frequency variability in the Slope Water we calculated surface geostrophic velocities from the altimeter data. The along-isobath velocities at the $1 / 4^{\circ} \times 1 / 4^{\circ}$ grid were obtained by interpolating the across-track velocity in the nearby altimeter lines. To eliminate the effect of the shelf break jet we defined the Slope Water as the region between the $1000 \mathrm{~m}$ and $3500 \mathrm{~m}$ isobaths. The ensemble (calculated by spatially averaging all data between the $1000 \mathrm{~m}$ and $3500 \mathrm{~m}$ isobaths) of the temperature and velocity were found to be correlated at the $95 \%$ significance level.

[13] The spatial structure of the surface velocity and temperature was explored by calculating their joint EOF. In order to obtain a first mode that is spatially homogeneous, stable in time and space, and well-separated from consecutive modes, the first three modes, explaining $25 \%$ of the variance, were rotated via VARIMAX rotation. The VARIMAX rotation maximizes the variance of the first mode and in cases where the leading modes are not wellseparated helps extract more physically meaningful modes [von Storch and Zwiers, 1999]. The first rotated mode (Figure 2) shows cooling and strengthening of the SW flow. This behavior is consistent over most of the domain, with larger velocity anomalies in the offshore region between $73 \mathrm{~W}$ and $71 \mathrm{~W}$, due to the direct influence of the Gulf Stream (a southerly path would be seen as a larger negative anomaly).

\section{Vertical Structure}

[14] Joyce et al. [2005] using direct velocity measurements (these stations were made on the $69 \mathrm{~W}$ line plotted in Figure 2) showed that the vertical structure of the mean DWBC was barotropic with maximum SW flows of several $\mathrm{cm} / \mathrm{sec}$. Here, however, our interest is in the variability.

[15] We observe that low potential vorticity anomalies at $69 \mathrm{~W}$ are associated with increased SW flow of the Slope Water. To take advantage of this co-variability and that anticipated from Figure 2, we calculated the joint EOF of 

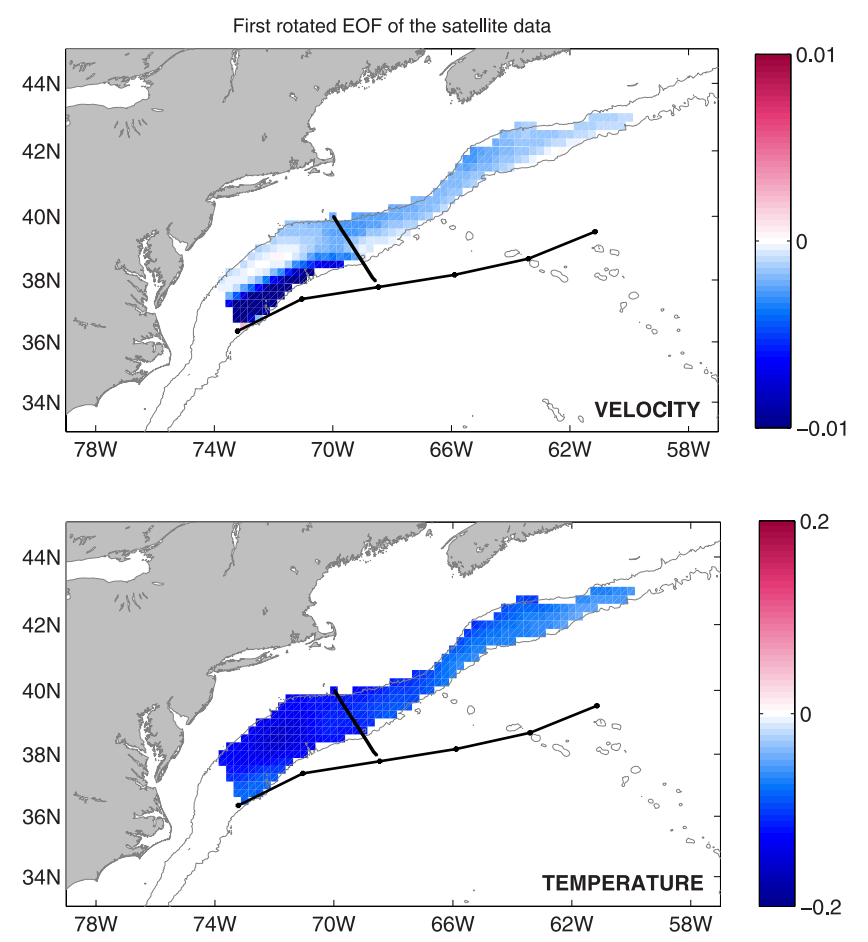

Figure 2. (top) First rotated EOF of the surface velocity and (bottom) SST anomalies. The black line is the Line W transect. The thin line is the mean position of the Gulf Stream.

the velocity, temperature, planetary potential vorticity (PPV) and salinity from the hydrographic sections. The first mode (Figure 3) explains $42 \%$ of the variability. A large fraction of the velocity variance on the hydrographic data at this location is known to be due to Topographic Rossby Waves (TRW) [Pickart and Watts, 1990]. For a plane wave, in the quasigeostrophic approximation, the temperature and horizontal velocity are $90^{\circ}$ out of phase. The EOF1 has velocity and temperature in phase and thus the signal of the TRW will be most likely scattered in higher modes.

[16] The surface signature of the velocity and temperature fields in the EOF1 of the hydrographic data is consistent with the surface analysis. The vertical structure of the mode reveals that in this region the variability despite being surface intensified, has a strong barotropic character.

[17] The distribution of salinity is remarkably similar to that of the temperature. Lower salinities are found in areas where temperature anomalies are negative, whereas higher salinities are found in areas of positive temperature anomalies. PPV reveals quite a different picture. The most striking feature is the large PPV anomaly centered at $1000 \mathrm{~m}$ and extending $200 \mathrm{~km}$ offshore occupying the Labrador Sea Water (LSW) depth range. Low PPV anomalies are thus linked with this leading EOF to low temperature, low salinity and high SW flow in the Slope Water.

[18] The agreement between the vertical and surface modes is not limited to their spatial structure. The PC1 of the satellite and hydrographic data are shown in Figure $4 \mathrm{~b}$. It can be seen that the circulation in the Slope Water fluctuates with periods around 3 years, although the time span of the Line $\mathrm{W}$ sections is too short to provide a statistically significant comparison.

\section{Summary and Discussion}

[19] The lag-correlation between the GS path fluctuations and SST anomalies shows that warming in the Slope Water

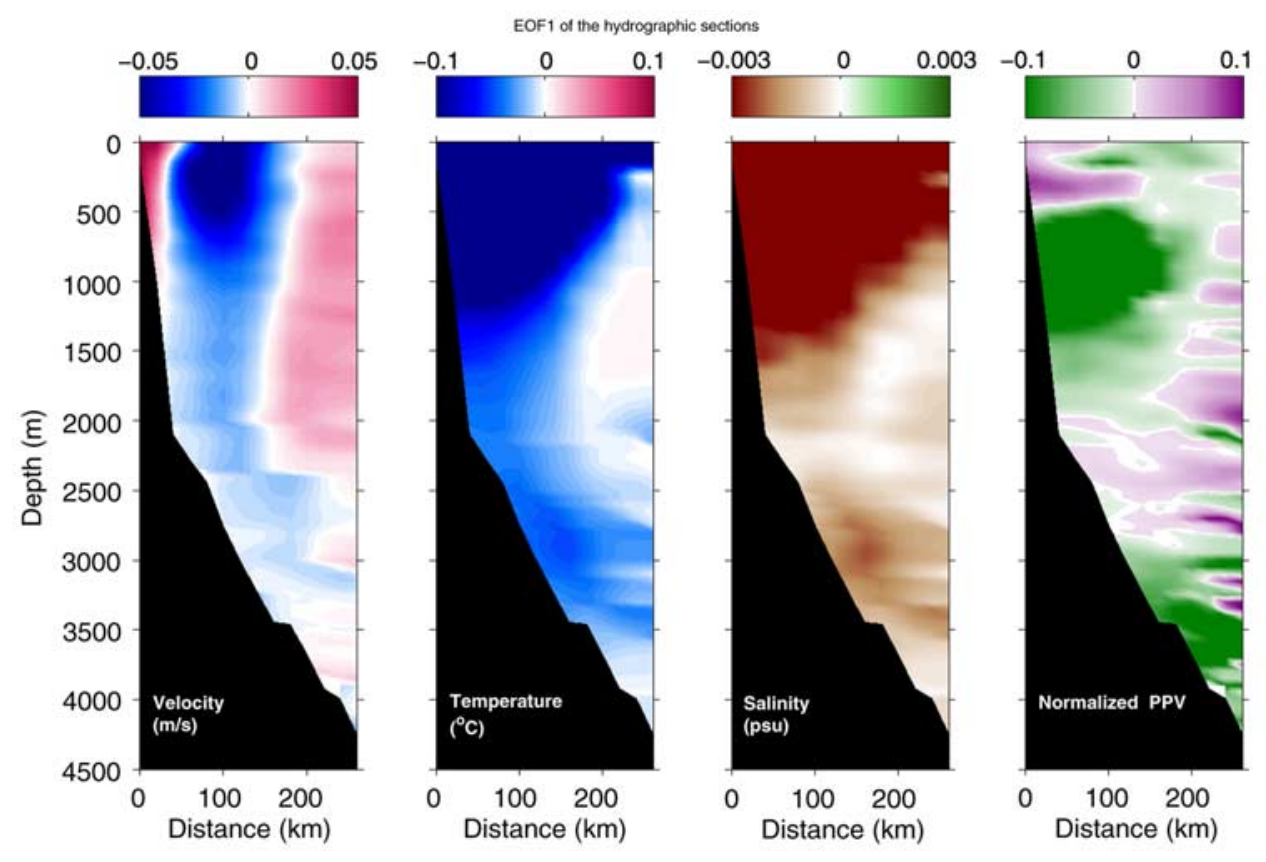

Figure 3. First EOF of the hydrographic sections at $69 \mathrm{~W}$ : anomalies of along-slope velocity $(\mathrm{m} / \mathrm{s})$, temperature $\left({ }^{\circ} \mathrm{C}\right)$, salinity (psu), and normalized PPV $\left(\left(f \cdot N^{2}\right)_{i} /\left(\overline{f \cdot N^{2}}\right)_{i}\right.$, the overbar denotes time average and i denotes the element in the section). 

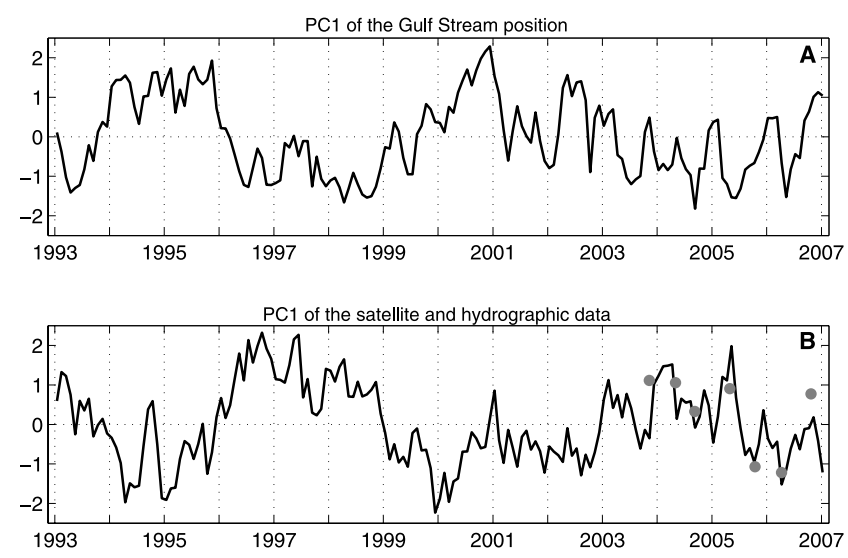

Figure 4. (a) $\mathrm{PC} 1$ of the GS path (positive values meaning the Gulf Stream is north of its mean path). The mean spatial displacement associated with this mode is approximately $50 \mathrm{~km}$. (b) PC1 of the satellite data, shown by the line, and hydrographic data, shown by the dots. Tick marks located on January 1 st.

precedes northward shifts of the stream. The warming does not occur simultaneously over the entire region, but progressively from the region west of Grand Banks, to the separation point of the Gulf Stream at Cape Hatteras. This signal moves with speeds of several $\mathrm{cm} / \mathrm{s}$, consistent with typical advection velocities in the area.

[20] The ensemble of the surface velocity and SST anomalies in the Slope Water are significantly correlated. The spatial distribution of their joint variability shows that cooling and intensification of the SW flow occur simultaneously and affect the entire slope. Except for the region directly affected by the Gulf Stream where the velocity anomalies can be at times as large as $40 \mathrm{~cm} / \mathrm{sec}$, the largest velocity anomalies associated with this mode do not exceed $5 \mathrm{~cm} / \mathrm{sec}$. This upper bound for the velocity anomalies is smaller than the mean SW flow derived from the coherence between the SST anomalies and the GS path, and suggests that the mode of variability described here does not imply flow reversals, unlike the seasonal cycle described by Dong and Kelly [2003], but substantial strengthening or weakening of the SW flow.

[21] The leading mode of variability of the velocity, salinity and temperature inferred from the hydrographic data at $69 \mathrm{~W}$ shows that the stronger fluctuations occur in the upper $1000 \mathrm{~m}$ of the water column. The amplitude of the fluctuations decreases with increasing depth but its sign remains constant. Like the surface, the deeper Slope Water is characterized by temperature and velocity anomalies of the same sign. The phase relations between the velocity, salinity and temperature anomalies captured by this mode agree with those found by Flagg et al. [2006]. They showed that a large fraction of the interannual variability in the temperature and salinity of the upper $500 \mathrm{~m}$ of the Slope Water were explained by advection. Cold and fresh periods being the result of stronger SW alongshore flow.

[22] Gulf Stream PC1 and the first rotated principal component of the surface temperature and velocity data are anti-correlated, as can be seen in Figure 4. The maximum value of the correlation, -0.6 , is found when temper- ature and velocity lead the GS path by 6 months. This lag is smaller than that reported by Zhang and Vallis [2006]. They found that northward shifts of the Gulf Stream followed positive temperature anomalies by about 1 year. This disagreement might be partially explained by the spatial differences in the lag which the EOF is unable to capture.

[23] The equivalent barotropic nature of the velocity variability in the Slope Water implies that stronger SW surface velocities are the surface signature of larger transports in the DWBC. Therefore decreasing temperatures and increasing transport in the DWBC lead to southward shifts of the Gulf Stream. This agrees with the relation found between SST in the slope and fluctuations in the Gulf Stream mean axis and supports the results by Thompson and Schmitz [1989].

[24] Surface velocities in our analysis do not exhibit any trend. Häkkinen and Rhines [2004] found that the slowing down of the circulation in the North Atlantic was not significant in the subtropics. The fluctuations from the trend in their SSH PC1 are in good agreement with the temporal patterns shown here, and suggest that this mode of variability may have a basin wide signature.

[25] According to our results, changes in the properties and circulation of the Slope Water are observed preceding latitude shifts in the Gulf Stream axis. These changes that affect the entire water column and move SW along the slope, can be observed at the surface and may therefore provide predictability for GS path changes.

[26] Acknowledgments. The repeated hydrographic sections were provided by the Line W project (NSF Grant OCE-0241354). We thank Mike Caruso and Charmaine King for processing the SSH data. The NOAA Optimum Interpolation 1/4 Degree Daily Sea Surface Temperature Analysis was obtained from the website http://www.ncdc.noaa.gov.

\section{References}

Berloff, P., A. M. Hogg, and W. Dewar (2007), The turbullent oscillator: The mechanics of low-frequency variability of the wind-driven ocean gyres, Journal of Physical Oceanography, in press.

Bower, A. S., and H. D. Hunt (2000), Lagrangian observations of the Deep Western Boundary Current in the North Atlantic Ocean. Part II: The Gulf Stream-Deep Western Boundary Current crossover, J. Phys. Oceanogr., 30, 784-804.

Cornillon, P. (1986), The effect of the New England Seamounts on Gulf Stream meandering as observed from satellite IR imagery, J. Phys. Oceanogr., 16, 386-389.

Dong, S., and K. A. Kelly (2003), Seasonal and interannual variations in geostrophic velocity in the Middle Atlantic Bight, J. Geophys. Res., 108(C6), 3172, doi:10.1029/2002JC001357.

Ezer, T., and G. L. Mellor (1992), A numerical study of the variability and the separation of the Gulf Stream induced by surface atmospheric forcing and lateral boundary flows, J. Phys. Oceanogr., 22, 660-682.

Flagg, C. N., M. Dunn, D. Wang, H. T. Rossby, and R. L. Benway (2006), A study of the currents of the outer shelf and upper slope from a decade of shipboard ADCP observations in the Middle Atlantic Bight, J. Geophys. Res., 111, C06003, doi:10.1029/2005JC003116.

Frankignoul, C., C. D. Coetlogon, T. M. Joyce, and S. Dong (2001), Gulf Stream variability and ocean-atmosphere interactions, J. Phys. Oceanogr. 31, 3516-3529.

Häkkinen, S., and P. B. Rhines (2004), Decline of Subpolar North Atlantic Circulation during the 1990s, Science, 304, 555-559.

Joyce, T. M., C. Deser, and M. Spall (2000), The relation between decadal variability of Subtropical Mode Water and the North Atlantic Oscillation, J. Clim., 13, 2550-2569.

Joyce, T. M., J. Dunworth-Baker, R. S. Pickart, D. Torres, and S. Waterman (2005), On the Deep Western Boundary Current south of Cape Cod, Deep Sea Res., Part II, 52, 615-625.

Kelly, K. A., and S. T. Gille (1990), Gulf Stream surface transport and statistics at $69^{\circ}$, from the Geosat altimeter, J. Geophys. Res., 96, $2161-3149$. 
Kelly, K. A., M. J. Caruso, and S. Singh (1996), Observations of atmosphere-ocean coupling in midlatitude, J. Geophys. Res., 101, 6295-6312.

Lee, T., and P. Cornillon (1995), Temporal variation of meandering intensity and domain-wide lateral oscillations of the Gulf Stream, J. Geophys. Res., 100, 13,603-13,613.

Pickart, R. S., and W. M. Smethie (1993), How does the Deep Western Boundary Current cross the Gulf Stream?, J. Phys. Oceanogr., 23, $2602-$ 2616.

Pickart, R. S., and D. R. Watts (1990), Deep Western Boundary Current variability at Cape Hatteras, J. Mar. Res., 48, 765-791.

Reynolds, R. W., T. M. Smith, C. Liu, D. B. Chelton, K. S. Casey, and M. G. Schlax (2006), Daily High-Resolution Blended Analyses for Sea Surface Temperature, J. Clim., in press.

Rossby, T. (1999), On gyre interactions, Deep Sea Res. Part II, 46, $139-$ 164.

Rossby, T., and R. L. Benway (2000), Slow variations in mean path of the Gulf Stream east of Cape Hatteras, Geophys. Res. Lett., 27, 117-120.
Spall, M. A. (1996), Dynamics of the Gulf Stream/Deep Western Boundary Current crossover. Part I: Entrainment and recirculation, J. Phys. Oceanogr., 26, 2152-2168.

Thompson, J. D., and W. J. Schmitz (1989), A limited area model of the Gulf Stream: Desing, initial experiments and model-data intercomparison, J. Phys. Oceanogr., 19, 791-814.

von Storch, H., and F. W. Zwiers (1999), Statistical Analysis in Climate Research, Cambridge Univ. Press, Cambridge, U. K.

Zhang, R., and G. K. Vallis (2006), Impac of great salinity anomalies on the low-frequency variability of the North Atlantic climate, J. Clim., 19, $470-482$.

Zhang, R., and G. K. Vallis (2007), The role of bottom vortex stretching on the path of the North Atlantic Western Boundary Current and the Northern Recirculation Gyre, J. Phys. Oceanogr., 37, 2053-2080, doi:10.1175 JPO3102.1.

B. Peña-Molino and T. M. Joyce, Woods Hole Oceanographic Institution, MS 21, Woods Hole, MA 02543, USA. (bpena-molino@whoi.edu) 